\title{
A educação ambiental como instrumento de sensibilização para reutilização de resíduos sólidos
}

\section{Environmental education as an awareness tool for solid waste reuse}

\author{
Elicarla Barbosa Moitinho ${ }^{* 1}$, Gabriella Moreira Campos $^{2}$, Igor Bruno Machado ${ }^{3}$, Dayane Mayara Figueredo ${ }^{4}$, Icaro Matheus \\ França Mendes ${ }^{5}$, Ricélia Maria Marinho Sales ${ }^{6}$
}

\begin{abstract}
Resumo: A inserção da educação ambiental no recinto escolar tem grande relevância nas mobilizações efetivas para o desenvolvimento sustentável. Dessa forma, objetivou-se desenvolver estratégias de sensibilização para disseminação dos princípios da educação ambiental junto a discentes do ensino médio de uma escola estadual situada em Pombal, Paraíba. Os procedimentos metodológicos pautaram-se em três etapas: a observação não participante; a realização de rodas de conversas com elementos estruturados visando à quantificação; e a inserção de atividades de reutilização de resíduos sólidos, objetivando iniciar um processo de sensibilização dos estudantes a partir da prática. Os resultados da análise revelaram que a Educação Ambiental no ambiente escolar se dá de maneira sucinta, contribuindo com uma lacuna que dificulta a compreensão de integração entre a natureza e a sociedade, ressaltando apenas a ideia de que as questões ambientais resumem-se apenas às noções do conservadorismo e da natureza como algo intocável, desenraizando a responsabilidade de cada indivíduo na construção de uma identidade planetária.
\end{abstract}

Palavras-chave: Cidadania planetária; Estratégias; Relação sociedade-natureza.

\begin{abstract}
The insertion of environmental education in the school district has great relevance in effective mobilizations for sustainable development. In this way, the objective of this work was to develop awareness-raising strategies to disseminate the principles of environmental education among high school students of a public school located in the city of Pombal Paraíba. The methodological procedures were based on three stages: non-participant observation; the realization of conversational groups with structured elements aimed at quantification; and the insertion of solid waste reuse activities, aiming to initiate a process of sensitizing students from the practice. The results of the analysis revealed that Environmental Education in the school environment is succinct, contributing to a gap that makes it difficult to understand the integration between nature and society, emphasizing only the idea that environmental issues are limited to the notions conservatism and nature as something untouchable, uprooting the responsibility of each individual in the construction of a planetary identity.
\end{abstract}

Key words: Planetary citizenship; Strategies; Relationship between society and nature.

\footnotetext{
Trabalho apresentado no III Simpósio de Ciências e Tecnologia (III SIMTAGRO), realizado entre 02 a 06 de outubro de 2017 no Centro de Ciências e Tecnologia Agroalimentar da Universidade Federal de Campina Grande, Pombal, Paraíba.

*Autor para correspondência

Recebido para publicação em 05/11/2017; aprovado em 21/11/2017

${ }^{1}$ Estudante de Engenharia Ambiental; Universidade Federal de Campina Grande, Pombal, Paraíba. (83) 981825881, elicarlamoitinho@gmail.com

${ }^{2}$ Estudante de Engenharia Ambiental; Universidade Federal de Campina Grande, Pombal, Paraíba. moreiragabriella84@gmail.com

${ }^{3}$ Estudante de Engenharia Ambiental; Universidade Federal de Campina Grande; Pombal, Paraíba. ibrunoanjos@ gmail.com

${ }^{4}$ Estudante de Engenharia de Alimentos; Universidade Federal de Campina Grande; Pombal, Paraíba. mayara.figueredo18@gmail.com

${ }^{5}$ Estudante de Engenharia Ambiental; Universidade Federal de Campina Grande; Pombal, Paraíba. icaromeendes@gmail.com

${ }^{6}$ Doutora, Professora da Universidade Federal de Campina Grande; Pombal, Paraíba , riceliamms@gmail.com
} 


\section{INTRODUÇÃO}

Após a revolução industrial, a sociedade aumentou seu consumo de forma significativa, o que contribui na produção de rejeitos que acabam se acumulando no meio ambiente, pela falta de gestão dos resíduos sólidos. Essa situação causa vários tipos de impactos, que se estendem ao social, como miséria e fome (ZANETTI, 2002). Desse modo, na atual realidade do âmbito social brasileiro, é perceptível a preocupação crescente sobre temas de destaque para a questão ambiental.

O trabalho com reciclagem e reuso de materiais, por exemplo, é uma atividade que vem, cada vez mais, sendo explorada por empresas de diversos países desenvolvidos, devido a sua importância social, econômica e ambiental. No Brasil a Lei 12.305, de 02 de agosto de 2010, instituiu a Política Nacional de Resíduos Sólidos (PNRS) e estabelece, entre outros quesitos, a reciclagem e reutilização dos resíduos como uma das suas premissas (BRASIL, 2010).

Segundo Santos et al. (2004), independente das características de uma região as políticas de administração de resíduos sólidos é de fundamental importância para a população do mundo e deve ser construído para que seja autossustentável. Além disso, o desenvolvimento de tecnologias inovadoras no mercado de reciclado assume um papel muito importante no Brasil, pois deve possibilitar um sistema de coleta inovador de baixo custo e eficiente através da centralização dos esforços individuais de catadores, aliado com o comprometimento entre custo de mercado e aplicação, adequação da flutuação do mercado e preços.

Associado ao atual cenário de crise ecológica e social está o argumento de que a população em geral tem uma visão de meio ambiente como algo intocado, de difícil valoração econômica e isento da relação com o mundo cultural humano (LENZI, 2006). A relação entre sociedade, educação e meio ambiente é muito complexa. Esta envolve diversos indivíduos do mundo educativo em diferentes níveis, promovendo a troca de muito conhecimento (JACOBI et al., 2009).

A escola, por sua vez, constitui-se um espaço de formação e troca de conhecimento e, por conta disso, se torna um lugar propício para divulgação de ideias economicamente sustentáveis, como por exemplo, reciclagem e reuso de resíduos. E para isso, é competência do poder público também assegurar que a educação ambiental esteja presente em todos os níveis de ensino.

Para Valdanha Neto e Kawasaki (2015), a Educação Ambiental enfrenta muitos obstáculos na configuração curricular pela hegemonia de disciplinas tradicionais que dificulta a implementação de práticas interdisciplinares por professores, mas sua crescente presença nas propostas curriculares é muito importante para que a temática esteja cada vez mais presente na sociedade.

Diante disso, a educação ambiental mostra-se como uma das muitas ferramentas existentes na atualidade, que tem como objetivo construir novas formas da sociedade se correlacionar com o meio ecológico (SOARES, 2016).

Com isso, o trabalho objetivou desenvolver estratégias de sensibilização para disseminação dos princípios da educação ambiental, através da disciplina de empreendedorismo para a realização de atividades que visassem o reaproveitamento de resíduos sólidos, junto aos discentes do ensino médio de uma escola estadual, situada em Pombal no estado da Paraíba.

\section{MATERIAL E MÉTODOS}

O método utilizado foi o da pesquisa-ação (HENRIQUES et al., 2007), no qual se apresentaram os conceitos de educação ambiental para a inserção de uma proposta de práticas extracurriculares de reaproveitamento de resíduos sólidos, mostrando a importância da construção de valores sociais e habilidades voltadas à conservação do meio ambiente.

Assim, os procedimentos adotados pautaram-se na estratégia de rodas de conversas (MONNERAT et al., 2016; SAMPAIO et al., 2014) com elementos estruturados visando à quantificação como elementos científicos que caracterizam uma pesquisa em uma escola estadual, situada no município de Pombal no estado da Paraíba, com doze educandos do ensino médio, de idades entre 16 a 19 anos. Em princípio, foi observada a relação entre professores e alunos durante as aulas, visando à obtenção de dados quanto ao ambiente escolar, ao relacionamento entre professores e alunos e uma relação entre o ensino e a aprendizagem escolar.

No que se refere ao ambiente escolar foram analisadas itens como arborização e limpeza da escola, que foram avaliados em escala de 1 a 5 sendo que1- Péssimo; 2 -Ruim; 3- Regular; 4- Bom 5- Excelente.

Quanto às relações: educador $\mathrm{x}$ educando $\mathrm{e}$ ensino $\mathrm{x}$ aprendizado foram analisados itens como conversa paralela entre os alunos e participação nas aulas, que foram avaliados de 1 a 5, sendo que 1- Péssimo; 2 -Ruim; 3-Regular; 4- Bom 5- Excelente.

Então, a estratégia foi organizar as inquietudes dos jovens participantes em um elemento estrutural que se aproxima de um questionário, mas o difere no processo de elaboração haja vista que as perguntas norteadoras surgem durante a interação do grupo (facilitadores e participantes), na etapa da observação foram identificadas as indagações e assim foi obtido um resultado prévio.

Por meio de vídeos e exposição oral foram realizadas discussões em sala de aula sobre educação ambiental e sustentabilidade. Após a abordagem temática foram levantadas as indagações para verificar se houveram modificações nas posturas e no modo de interpretar a realidade, então na sequência houve a provocação para revisitar as indagações iniciais para verificar se houve alguma alteração na compreensão sobre as questões que compõem a relação sociedade-natureza. E assim, foi possível verificar o feedback (DIMOTAKIS et al., 2017) entre os conteúdos repassados e a compreensão de cada indivíduo (educandos).

De modo prático, utilizaram-se das bases da interdisciplinaridade (MARTINS et al., 2017) para conectar as disciplinas de Princípios e Estratégias da Educação Ambiental com Empreendedorismo e, foi sugerida, aos educandos, a criação de uma empresa fictícia de reciclagem de resíduos sólidos.

\section{RESULTADOS E DISCUSSÃO}

As estratégias de sensibilização para disseminação dos princípios da educação ambiental apresentavam efeitos positivos durante o período de interação entre a equipe de universitários e a comunidade escolar. Houve o envolvimento dos discentes no tocante à interação e à participação individual e em grupo. Referente ao feedback entre os conteúdos repassados e à compreensão de cada indivíduo (educandos), foi possível verificar a partir da análise das indagações seguindo a estratégia da roda de conversa. 
Havia no instrumento de pesquisa a questão sobre a importância da separação do lixo orgânico e inorgânico, uma vez que o acúmulo de lixo em conjunto com a destinação incorreta é um dos principais problemas na atualidade.

$\mathrm{Na}$ análise inicial, observou-se que nenhum dos alunos estava ciente da importância da separação do lixo orgânico e inorgânico para sua destinação correta, portanto não havia empenho na divisão desses resíduos em seus domicílios. Após a roda de conversa, com o entendimento dos alunos, foi observado que $60 \%$ dos educandos apontaram o interesse em promover mudanças de hábitos e o desejo em realizar separação do lixo em suas residências (Figura 1). Da mesma maneira, segundo Brum e Silveira (2011), foi possível constatar que as pessoas ainda não tinham esclarecimentos suficientes em relação à destinação do lixo, embora alguns sentissem a necessidade de modificar esse fato.

Acerca do conhecimento dos alunos no que se refere ao tempo hábil da degradação do vidro no meio ambiente, apenas $11,1 \%$ do total de alunos tinham essa informação. Após as explanações, $30 \%$ da turma dos educandos compreenderam que o tempo de degradação do vidro é indeterminado (Figura 1).

Sobre o princípio dos " $3 \mathrm{Rs}$ " da sustentabilidade (reduzir, reutilizar e reciclar), 11,1\% do grupo de alunos tinham conhecimento sobre o tema. No entanto, no segundo momento, houve um grande aumento no conhecimento, assim $90 \%$ destes souberam responder o que se tratava. No que diz respeito à reutilização de resíduos, $100 \%$ afirmaram que sabiam da importância dessa prática, levando em consideração a tentativa de reduzir o descarte de resíduos sólidos disseminados no meio ambiente (Figura 1).

No tocante ao interesse na participação de atividades de reciclagem, inicialmente $22 \%$ dos alunos demonstraram interesse. Após os conhecimentos adquiridos, o interesse nessa prática aumentou para 40\% (Figura 1). Em relação aos questionamentos sobre a empresa sustentável, observa-se na figura 1 que visando à reutilização dos resíduos sólidos, 55\% dos discentes tinham conhecimento sobre as práticas de uma empresa sustentável. Após os conhecimentos adquiridos, $60 \%$ dos estudantes entenderam do que se tratava e propuseram a reutilizar potes de vidros.

De acordo com uma análise feita em um colégio, segundo Saraiva et al. (2008), é possível verificar a preocupação das crianças na preservação dos ecossistemas do lugar em que vivem e há o interesse em realizar práticas para atenuar os desperdício.

Figura 1. Opiniões dos alunos antes e após a aprendizagem sobre educação ambiental e sustentabilidade, Pombal Paraíba.

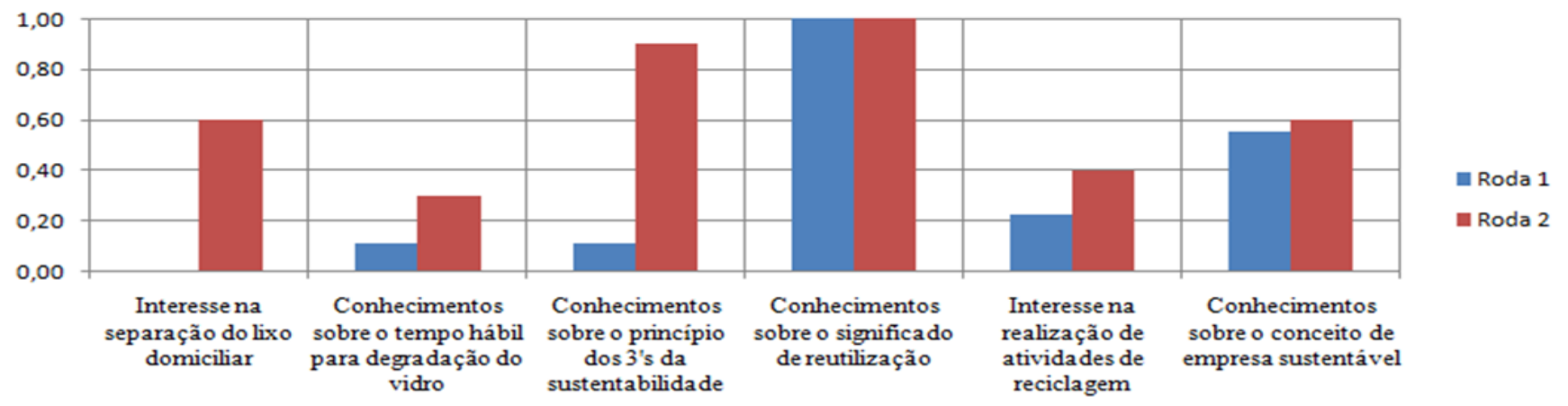

Com a atividade da criação de uma empresa de reciclagem de materiais e resíduos sólidos foi realizada uma oficina de customização visando o reaproveitamento de potes de vidro e os transformando em objetos decorativos que foram expostos e receberam uma premiação durante a realização da feira de ciências da escola.

As práticas educativas de caráter sustentável nos conduzem para propostas pedagógicas centradas na análise crítica e na emancipação dos sujeitos, tendo como objetivo à mudança de comportamento e atitudes, aspirando ao

desenvolvimento da cidadania planetária (JACOB et al., 2009).

Na Tabela 1 observa-se que ambiente escolar mantevese limpo, apesar de em alguns espaços não apresentarem lixeiras. A área verde da escola foi classificada como regular, já que havia certa arborização no local, deixando o ambiente um pouco mais arejado e com sensação de bem estar. Contudo, foi observado o uso de ar-condicionado dentro das salas de aula, que impossibilitou a abertura das janelas, o que promove um maior gasto de energia.

Tabela 1. Informações quanto o ambiente escolar observado em Escola estadual em Pombal, Paraíba

\begin{tabular}{lc}
\hline \multicolumn{1}{c}{ Informação } & Pontos \\
\hline Ambiente escolar é limpo & 4 \\
As salas de aula são arejadas & 2 \\
A iluminação das salas é adequada & 4 \\
Existem barulhos que interferem a concentração dos alunos & 3 \\
Há comunicação professores e alunos & 4 \\
Existe área verde e jardins na escola & 3 \\
O espaço é amplo e existe sensação de bem estar & 3 \\
Há lixeiras distribuídas nas áreas comuns (ex.: pátios, corredores, etc.) & 4 \\
Há lixeiras nas salas de aula & 1 \\
Verificou-se o desperdício de papel & 2 \\
Verificou-se o desperdício de água & 2 \\
Verificou-se o desperdício de comida & - \\
Verificou-se o desperdício de energia & 2 \\
\hline
\end{tabular}

Revista Verde, v.12, n.5, p.874-878, 2017 
Na Tabela 2 verifica-se a dificuldade de repasse de conteúdos com elementos de interdisciplinaridade, já que demanda dos professores um maior conhecimento sobre outras áreas de estudo.

É necessário que no processo de aprendizagem sobre a sustentabilidade socioambiental se reconheça o meio ambiente como bem público e que o acesso deva ser de maneira saudável como um direito de cidadania (JACOB et al., 2009).

Para se realizar a interdisciplinaridade é imprescindível que o educador domine a área do conhecimento e a matéria a qual almeja ministrar suas aulas, pois é necessário relacionar os saberes. A interdisciplinaridade constrói a relação entre os conhecimentos das diversas áreas (MARTINS et al., 2017).

Tabela 2: Informações quanto as relações Educador x Educando e Ensino x Aprendizado observado em Escola estadual em Pombal, Paraíba

\begin{tabular}{lc}
\hline \multicolumn{1}{c}{ Informação } & Pontos \\
\hline Há participação dos alunos durante a apresentação dos conteúdos & 4 \\
Há utilização dos recursos didáticos durante as aulas & 3 \\
Há conversa paralela entre os alunos & 1 \\
Há conflito entre os professores e alunos & 5 \\
Há alunos que tentam desviar as atenções dos demais & 1 \\
A aula foi criativa & 2 \\
O conteúdo foi passado com clareza e segurança & 4 \\
O professor foi além do repasse de conteúdos motivando os alunos a conhecer mais sobre o tema & 2 \\
Durante a apresentação do conteúdo foi destacado elementos de interdisciplinaridade & 2 \\
Durante a apresentação do conteúdo foi destacado elementos da transversalidade da EA & 1 \\
A arborização e outros aspectos fazem parte dos conteúdos programáticos a ser abordados por mais de uma & \\
disciplina
\end{tabular}

\section{CONCLUSÕES}

A efetivação da estratégia da roda de conversa é uma excelente ferramenta para iniciar o processo de sensibilização e disseminação dos princípios da educação ambiental junto aos jovens, haja vista a comprovação de um feedback relevante demonstrando que os discentes além de demonstrar o interesse em absorver os novos conteúdos, também manifestaram o desejo em mudar hábitos e costumes, ao passo que irão tentar implantar em suas residências.

A criação da empresa de reciclagem de materiais e resíduos sólidos e, consecutivamente a premiação durante a feira de ciências da escola destacou-se como um elemento motivador para os jovens, que verbalizaram sobre a comprovação do papel importante que a educação ambiental pode assumir para atenuar a crise ambiental existente, ao passo que pode transformar vidas de pessoas que necessitam se inserir ao sistema socioeconômico, mas priorizando os princípios da sustentabilidade. Para tanto, é necessário que haja qualificação, instrumentação e estruturas adequadas que garantam a saúde dos trabalhadores, da sociedade e da natureza para promover o possível e sonhado desenvolvimento sustentável.

\section{REFERÊNCIAS}

BRASIL. Presidência da República. Casa Civil. Subchefia para assuntos jurídicos. Lei $\mathrm{n}^{\circ} 12.305$, de 2 de agosto de 2010. Institui a Política Nacional de Resíduos Sólidos; altera a Lei no 9.605, de 12 de fevereiro de 1998; e dá outras providências. Disponível em: http://www.planalto.gov.br/ccivil_03/_ato20072010/2010/lei/ 112305.htm. Acesso em: 22 de Jan. 2018.

BRUM, D. P.; SILVEIRA, D. D. Educação ambiental na escola: Da coleta seletiva do lixo ao aproveitamento do resíduo orgânico. Revista Eletrônica em Gestão, Educação e Tecnologia Ambiental, v.4, n.4, p.608-617, 2011.

DIMOTAKIS, N.; MITCHELL, D.; MAURER, T. Positive and Negative Assessment CenterFeedback in Relation to Development Self-Efficacy, Feedback Seeking, and Promotion. Journal of Applied Psychology, American Psychology Association, v.102, n.11, p. 1-14, 2017.

HENRIQUES, R.; TRAJBER, S; LIPAI, E. M.; CHAMUSCA, A. Educação Ambiental: aprendizes de sustentabilidade. CADERNOS SECAD 1. Brasília - DF: Ministério da Educação, 2007.

JACOBI, P. R.; TRISTÃO, M.; FRANCO, M. I. G. C. A função social da educação ambiental nas práticas colaborativas: Participação e engajamento. Cad. Cedes, Campinas, v.29, n.77, p.63-79, 2009.

LENZI, C. L. Para uma imaginação sociológica da ecologia: uma análise do pensamento de Anthony Giddens. Revista Ambiente e Sociedade. v.9, n.1, 2006.

MARTINS, F. J.; SOLDÁ, M.; PEREIRA, N. F. F. Interdisciplinaridade: da totalidade à prática pedagógica. Revista Interdisciplinar em Ciências Humanas, INTERthesis, v.14, n.1, p.01-18, 2017.

MONNERAT, C. P.; SILVA, L. F.; SOUZA, D. K.; AGUIAR, R. C. B.; CURSINO, E. G.; PACHECO, S. T. A. Estratégia de educação em saúde com familiares de crianças em uso contínuo de medicamentos. Revista de Enfermagem UFPE (online), v.10, n. 11, p.3814 -3823, 2016.

SAMPAIO, J.; SANTOS, G. C.; AGOSTINI, M.; SALVADOR, A. S. Limites e potencialidades das rodas de conversa no cuidado da saúde: uma experiência com jovens 
no Sertão pernambucano. Interface (Botucatu), v.18, n.2, p.1299-1312, 2014.

SANTOS, A. S. F.; AGNELli, J. A. M.; MANRICH, S. Tendências e desafios da reciclagem de embalagens plásticas. Ciência e Tecnologia, v.14, n5, p.307-312, 2004.

SARAIVA, V. M.; NASCIMENTO, K. R. P. do; COSTA, R. K. P. da. A prática pedagógica do ensino de educação ambiental: nas escolas públicas de joão câmara- RN. Holos, João Câmara Rn, v.2, p.81-93, 2011.

SOARES, J. C. Educação ambiental na educação infantil: Brincadeiras com a turma do "sapinho amigo". 2016, 89f. Trabalho de conclusão de curso, Universidade Estadual Paulista Júlio de Mesquita Filho, Rio Claro, 2016.

VALDANHA NETO, D.; KAWASAKI, C. S. A temática ambiental em documentos curriculares nacionais do ensino médio. Ens. Pesqui. Educ. Ciênc., v.17, n.2, p.483-499, 2015.

ZANETTI, I. C. B. B; SÁ, L. M. A educação ambiental como instrumento de mudança na concepção de gestão dos resíduos sólidos domiciliares e na preservação do meio ambiente. 2002. Dissertação, Universidade de Brasília, Brasília, 2002. 